\title{
Dopaminergic Mechanisms of Individual Differences in Human Effort-Based Decision-Making
}

\author{
Michael T. Treadway, ${ }^{1 \star}$ Joshua W. Buckholtz, ${ }^{1,2 \star}$ Ronald L. Cowan, ${ }^{3,4,6}$ Neil D. Woodward, ${ }^{3,4}$ Rui Li, ${ }^{5}$ M. Sib Ansari, ${ }^{5}$ \\ Ronald M. Baldwin, ${ }^{5}$ Ashley N. Schwartzman, ${ }^{1}$ Robert M. Kessler, ${ }^{5}$ and David H. Zald ${ }^{1,3}$ \\ ${ }^{1}$ Department of Psychology, ${ }^{2}$ Vanderbilt Brain Institute, ${ }^{3}$ Department of Psychiatry, ${ }^{4}$ Psychiatric Neuroimaging Program, ${ }^{5}$ Department of Radiology, and \\ ${ }^{6}$ Vanderbilt Addiction Center, Vanderbilt University, Nashville, Tennessee 37240
}

Preferences for different combinations of costs and benefits are a key source of variability in economic decision-making. However, the neurochemical basis of individual differences in these preferences is poorly understood. Studies in both animals and humans have demonstrated that direct manipulation of the neurotransmitter dopamine (DA) significantly impacts cost/benefit decision-making, but less is known about how naturally occurring variation in DA systems may relate to individual differences in economic behavior. In the present study, 25 healthy volunteers completed a dual-scan PET imaging protocol with $\left[{ }^{18} \mathrm{~F}\right]$ fallypride and $d$-amphetamine to measure DA responsivity and separately completed the effort expenditure for rewards task, a behavioral measure of cost/benefit decision-making in humans. We found that individual differences in DA function in the left striatum and ventromedial prefrontal cortex were correlated with a willingness to expend greater effort for larger rewards, particularly when probability of reward receipt was low. Additionally, variability in DA responses in the bilateral insula was negatively correlated with willingness to expend effort for rewards, consistent with evidence implicating this region in the processing of response costs. These findings highlight the role of DA signaling in striatal, prefrontal, and insular regions as key neurochemical mechanisms underlying individual differences in cost/benefit decision-making.

\section{Introduction}

A common aspect of human economic behavior is that individuals differ in their valuation of costs and benefits. Variability in decisions about how much to work, how much to risk, or how long to wait for a given reward has been linked to specific facets of personality (Richards et al., 1999; Holt et al., 2003) and psychopathology (Bickel and Marsch, 2001; Forbes et al., 2007). However, the neurochemical mechanisms of these individual differences remain poorly understood.

Animal studies have implicated the neurotransmitter dopamine (DA) as playing a crucial role in cost/benefit decisionmaking. When choosing whether to consume freely available but less desirable food rewards (low effort) or to exert physical effort in exchange for more palatable food rewards (high effort), healthy rats exhibit a strong preference for the high-effort option. Interestingly, blockade of DA signaling results in a behavioral shift toward low-effort options (Cousins and Salamone, 1994; Salamone et al., 2007), whereas enhancement of DAerigc tone increases willingness to work for rewards (Bardgett et al., 2009).

\footnotetext{
Received Dec. 17, 2011; revised March 7, 2012; accepted March 9, 2012.

Author contributions: M.T.T., R.M.K., and D.H.Z. designed research; M.T.T., R.L.C., N.D.W., A.S., R.B., and R.M.K. performed research; M.T.T., J.W.B., R.L.C., N.D.W., R.L., M.S.A., and R.M.K. contributed unpublished reagents/ analytic tools; M.T.T., J.W.B., and R.L. analyzed data; M.T.T., J.W.B., and D.H.Z. wrote the paper.

This research was funded by National Institute on Drug Abuse Grant R01DA019670-04 (D.H.Z.) and National Institute of Mental Health Grants R21 MH092751 (D.H.Z.) and F31MH087015 (M.T.T.).

*M.T.T. and J.W.B. contributed equally to this work.

The authors declare no competing financial interests.

Correspondence should be addressed to Michael T. Treadway, 301 Wilson Hall, 11121 st Avenue South, Nashville, TN 37203.E-mail:m.treadway@vanderbilt.edu.

DOI:10.1523/JNEUROSCI.6459-11.2012

Copyright $\odot 2012$ the authors $\quad 0270-6474 / 12 / 326170-07 \$ 15.00 / 0$
}

Similar effects have been observed for studies of risk-related choice, with DA blockade associated with reduced willingness to choose riskier (but larger) rewards (St Onge and Floresco, 2009) (but see Zeeb et al., 2009), suggesting that alteration of DA neurotransmission may exert its influence primarily by helping the organism overcome response costs—such as effort requirements, probability of receipt, or temporal delay-that may discount the face value of the reward magnitude (Phillips et al., 2007; Salamone et al., 2007).

Recently, two studies in humans reported similar effects of DAergic attenuation and potentiation on cost/benefit decision-making. In a sample of smokers, dietary depletion of catecholamine precursors resulting in transient reduction of DA availability decreased the willingness to expend effort for cigarettes during a progressive ratio task (Venugopalan et al., 2011). Conversely, we recently reported that administration of $d$-amphetamine increased participants' willingness to endure effort and probabilistic costs to obtain monetary rewards as assessed by the effort expenditure for rewards task (EEfRT or "effort"), particularly under conditions of low probability (Wardle et al., 2011).

Given the previous findings presented by Wardle et al. (2011), the current study sought to evaluate whether variability in responsivity of the DA system was associated with individual differences in cost/benefit decision-making. As in our previous study, cost/benefit decision-making involving both effort and probabilistic costs was assessed with the EEfRT (Treadway et al., 2009; Wardle et al., 2011). We evaluated individual differences in DA function by measuring stimulant-induced change in $\mathrm{D}_{2} / \mathrm{D}_{3}$ receptor availability using a placebo-controlled, $d$-amphetamine 
Table 1. Sample demographics

\begin{tabular}{lc}
\hline Sex & $52 \%$ female, 48\% male \\
Race & $76 \%$ Caucasian, 16\% Asian-American, \\
& $8 \%$ African American \\
Age (years) & Average, 21.8; range, 18-29 \\
Recent tobacco use (past 6 months) & $0 \%$ \\
Recent alcohol use (past 6 months) & $56 \%$ \\
Recent alcohol use (average consumption) & 3 drinks per week ( \pm 4.8$)$ \\
Recent cannabis use (\%) & $12 \%$ \\
Recent stimulants use (\%) & $0 \%$ \\
Recent hallucinogen use (\%) & $0 \%$ \\
Recent sedatives or opioid use (\%) & $0 \%$ \\
Past alcohol use & $80 \%$ \\
Past alcohol (average consumption) & 4.6 drinks per week ( \pm 5.8$)$ \\
Past cannabis use (\%) & $24 \%$ \\
Past stimulants use (\%) & $4 \%$ \\
Past hallucinogen use (\%) & $4 \%$ \\
Past sedative or opioid use (\%) & $0 \%$ \\
\hline
\end{tabular}

cent use of alcohol or marijuana were allowed to continue in the study, provided that they abstained from any use of these substances until the study was complete. Urine drug screens were used to confirm drug abstinence over the course of the study. Behavioral data from seven participants in the current study were reported previously (Treadway et al., 2009). A summary of subject demographics is presented in Table 1.

EEfRT. The EEfRT is a multi-trial game in which participants are given an opportunity on each trial to choose between two different task difficulty levels to obtain varying monetary rewards (Fig. 1). A detailed description of the task has been published previously (Treadway et al., 2009). Briefly, each trial presents the subject with a choice between a "hard task" (high-effort option) and an "easy task" (low-effort option), which require different amounts of speeded manual button pressing. The easy task required 30 button presses with the subject's dominant-hand index finger in $7 \mathrm{~s}$, and the hard-task required 100 button presses in $21 \mathrm{~s}$ with the subject's non-dominant pinky finger. For easy-task choices, subjects were eligible to win the same amount, $\$ 1.00$, on each trial if they successfully completed the task. For hard-task choices, subjects were eligible to win higher amounts that varied per trial within a range of $\$ 1.24$ to $\$ 4.30$ ("reward magnitude"). Subjects were not guaranteed to win the reward if they completed the task; some trials were "win" trials, in which the subject received the stated reward amount for the chosen task, whereas others were "no-win" trials, in which the subject received no money for that trial. To help subjects determine which trials were more likely to be win trials, subjects were provided with accurate probability cues at the beginning of each trial. Trials had three levels of probability: "high," $88 \%$ probability of being a win trial; "medium," 50\%; and "low," 12\%. Probability levels always applied to both the hard task and easy task, and there were equal proportions of each probability level across the experiment.

PET image acquisition. Protocols for PET image acquisition and analysis have been published

challenge paradigm in conjunction with a dual-scan, PET imaging protocol with the $\mathrm{D}_{2} / \mathrm{D}_{3}$-specific ligand $\left[{ }^{18} \mathrm{~F}\right]$ fallypride.

\section{Materials and Methods}

Study design. The goal of the current study was to evaluate how variability in DA function was associated with individual differences in cost/benefit decision-making preferences. Subjects completed three testing sessions. The first two sessions involved completing a PET scan while receiving either a pill placebo or $d$-amphetamine challenge. During the third testing session, subjects completed the EEfRT. Importantly, subjects were not under the influence of $d$-amphetamine when completing the EEfRT. This design allowed us to assess how differences in DA system responsivity were associated with basal variation in cost/benefit preferences.

Participants. Twenty-five participants (52\% female) were studied as part of an ongoing investigation of individual differences in striatal and extrastriatal DA function. All participants were medically and psychiatrically healthy adults, 19-29 years of age. After initial screening, subjects were given an interview of their medical history and a structured psychiatric interview (Structured Clinical Interview for DSM Disorders for the Non-Patient). Subjects were excluded if they had any history of substance abuse, current tobacco use, and use of psychostimulants (excluding caffeine) more than twice in the subject's lifetime or at all in the past 6 months, any psychotropic medication for the past 6 months other than occasional use of benzodiazepines for sleep, history of psychiatric illness, significant medical condition, or any condition that would interfere in PET or magnetic resonance imaging (MRI) studies (e.g., extreme obesity, claustrophobia, cochlear implant, metal fragments in eyes, cardiac pacemaker, neural stimulator, metallic body inclusions or other metal implanted in the body, and pregnancy). Participants were also excluded if they had any contra-indications for receiving $d$-amphetamine (abnormal EKG, hypertension). Subjects who reported recent use (within the past 6 months) of tobacco products were excluded. Subjects who reported re- previously (Buckholtz et al., 2010a,b). All PET images were acquired using $\left[{ }^{18} \mathrm{~F}\right]$ fallypride [( $S)-N$ - [(1-allyl-2-pyrrolidinyl) methyl]-5-(3-[ $\left.{ }^{18} \mathrm{~F}\right]$ fluoropropyl)-2,3-dimethoxybenzamide], a substituted benzamide with very high affinity to $D_{2} / D_{3}$ receptors (Mukherjee et al., 2005). The use of $\left[{ }^{18} \mathrm{~F}\right]$ fallypride in the present context is critical in that, unlike other $\mathrm{D}_{2} / \mathrm{D}_{3}$ ligands, $\left[{ }^{18} \mathrm{~F}\right]$ fallypride allows stable estimates of $\mathrm{D}_{2}$-like binding in both striatal and extrastriatal regions (Mukherjee et al., 2002; Christian et al., 2004). It thus provides a unique ability to simultaneously examine human DA function in both cortical and striatal areas involved in cost/benefit decision-making. Previous work has demonstrated good test-retest reliability of $\left[{ }^{18} \mathrm{~F}\right]$ fallypride measurements of non-displaceable binding potential $\left(\mathrm{BP}_{\mathrm{ND}}\right)$ - a computed estimate of the number of available $\mathrm{D}_{2} / \mathrm{D}_{3}$ receptors - in both striatal and prefrontal areas (Mukherjee et al., 2002). Each subject received two $\left[{ }^{18} \mathrm{~F}\right]$ fallypride scans: the first was a baseline placebo scan, and the second scan occurred on a separate day and was performed while the subject received a 0.43 $\mathrm{mg} / \mathrm{kg}$ oral dose of $d$-amphetamine. Scans were not counterbalanced for several reasons. First and foremost, our study was designed to assess individual differences, and thus it was optimal to keep all aspects of the study design constant across subjects. Counterbalancing would require additional statistical control and would lower statistical power. Moreover, counterbalancing would impair maintenance of blinding, because most subjects receiving $d$-amphetamine during the first scan would be aware of receiving placebo for the second scan. Finally, conducting the $d$-amphetamine scans on the first scan day requires additional time between scan days, which is problematic for scheduling female participants, who were scheduled so as to ensure that both scans were conducted in the early follicular phase of their menstrual cycle for both scanning days. All PET scans were acquired on a GE Discovery STE system manufactured by GE Healthcare located at Vanderbilt University Medical Center. $\left[{ }^{18} \mathrm{~F}\right]$ Fallypride was produced in the radiochemistry laboratory attached to the PET unit, following synthesis and quality-control procedures de- 
scribed by the Food and Drug Administration (IND 47,245). Scans were timed to start $3 \mathrm{~h}$ after $d$-amphetamine administration, which was timed to coincide with the period of peak plasma $d$-amphetamine. 3 -D emission acquisitions scans were performed after a $5.0 \mathrm{mCi}$ slow bolus injection of $\left[{ }^{18} \mathrm{~F}\right]$ fallypride (specific activity $>3000 \mathrm{Ci} / \mathrm{mmol}$ ). Serial scans were started simultaneously with the bolus injection of $\left[{ }^{18} \mathrm{~F}\right]$ fallypride and were obtained for $\sim 3.5$ h, with two 15 min breaks for subject comfort. Low-dose computed tomography scans were collected for attenuation correction before each of the three emissions scans.

PET image processing. Each subject's serial PET scans were first corrected for motion across scanning periods using a mutual information-based rigid-body algorithm (Wells et al., 1996; Maes et al., 1997). Regional $\mathrm{D}_{2} / \mathrm{D}_{3} \mathrm{BP}_{\mathrm{ND}}$ was calculated on a voxelwise basis using the full (four compartment) reference tissue method (Lammertsma et al., 1996), with cerebellum chosen as the reference region because of its relative lack of $\mathrm{D}_{2} / \mathrm{D}_{3}$ receptors (Hall et al., 1994). We used the full model rather than a simplified reference region model because of concerns that have been raised previously about applying the simplified model to high-affinity ligands (Votaw et al., 1993). Using the full reference region method, we have shown near-perfect $(r=0.99)$ correlation with modeled estimates using a metabolitecorrected plasma input function (Kessler et al., 2000). Although this approach is slower computationally than the simplified (three parameter) tissue reference method, the two methods show nearly identical estimates of binding potential, and we have observed excellent convergence of modeled fits in regions with both high and low $\mathrm{D}_{2} / \mathrm{D}_{3}$ receptor levels. Voxelwise kinetic modeling was executed using Interactive Data Language (RSI).

Each participant's $\mathrm{BP}_{\mathrm{ND}}$ image was aligned with their T1-weighted MRI based on coregistration of the weighted average of the PET dynamic scans to the MRI using a mutual information-based rigid-body algorithm (Wells et al., 1996; Maes et al., 1997). Before group analyses, a composite binding potential image was created for each PET scan and warped to Montreal Neurological Institute (MNI) space using a non-rigid-body coregistration (Rohde et al., 2003). The transformation matrix from this warping was then applied to the $\mathrm{BP}_{\mathrm{ND}}$ statistical parametric maps (SPM) to bring them into MNI space. Using the "imcalc" routine as implemented in SPM5, voxelwise maps of the percentage change in $D_{2} / D_{3} B P_{N D}$ $\left(\% \Delta \mathrm{BP}_{\mathrm{ND}}\right)$ across the amphetamine- and placebo-day scans were created for each subject, providing an index of stimulant-induced DA responsivity. Voxelwise $\% \Delta \mathrm{BP}_{\mathrm{ND}}$ maps were inspected for any regions showing $\% \Delta \mathrm{BP}_{\mathrm{ND}}>50 \%$, which could arise as a result of misalignment across scan days. One subject showed evidence of this in a few voxels near the boundary of the putamen and insula. Because the insula was among the areas showing statistically significant effects, we analyzed the data both with and without these voxels for the subject included in the analysis. The results were significant in both cases, and we report the lower magnitude effect (with those voxels excluded) below.

Statistical methods. The primary dependent variable of the EEfRT is the proportion of high-effort choices made by each individual throughout the session. The effects of different levels of reward magnitude, probability, and expected value (reward magnitude $X$ probability) on the likelihood of making a hard-effort choice during the EEfRT were estimated using a single generalized estimating equation (GEE) (Zeger and Liang, 1986). The relationship between individual differences in choice behavior and variability in $\% \Delta \mathrm{BP}_{\mathrm{ND}}$ was assessed on a voxelwise basis using a multiple regression analysis as implemented in SPM5, with proportion of high-effort options as the primary independent variable and subject age
Table 2. Voxelwise correlations between EEfRT task performance and \% $\%$ BPND

\begin{tabular}{|c|c|c|c|c|c|c|}
\hline \multirow[b]{2}{*}{ Region } & \multicolumn{3}{|c|}{ Peak coordinates } & \multirow{2}{*}{$\begin{array}{l}\text { Peak } \\
\text { Z-score }\end{array}$} & \multirow{2}{*}{$\begin{array}{l}\text { Cluster size } \\
\text { (k) }\end{array}$} & \multirow{2}{*}{$\begin{array}{l}\text { Cluster } p \\
\text { value (corr.) }\end{array}$} \\
\hline & $x$ & $y$ & $z$ & & & \\
\hline \multicolumn{7}{|l|}{ Positive correlations } \\
\hline All trials & - & - & - & - & - & - \\
\hline \multicolumn{7}{|l|}{ Low-probability trials } \\
\hline vmPFC & 20 & 42 & -18 & 3.67 & 80 & $<0.001$ \\
\hline Left caudate & -8 & 10 & 14 & 3.45 & 71 & $<0.001$ \\
\hline VIPFC & -48 & 18 & 6 & 3.13 & 44 & 0.005 \\
\hline Inferior temporal gyrus & -56 & -18 & -22 & 4.13 & 41 & 0.018 \\
\hline \multicolumn{7}{|l|}{ Negative correlations } \\
\hline \multicolumn{7}{|l|}{ All trials } \\
\hline Left anterior insula & -24 & 22 & 10 & 5.55 & 206 & $<0.001$ \\
\hline Right anterior insula & 44 & 10 & -2 & 3.41 & 50 & 0.022 \\
\hline Low-probability trials & & & & & & \\
\hline
\end{tabular}

and gender included as covariates. We tested for regions showing both positive and negative correlations with proportion of high-effort options. Whole-brain correction for multiple comparisons was achieved using a cluster-extent correction procedure as implemented in SPM5. Only results surviving cluster correction $\left(p_{\text {cluster }}<0.05\right)$ are reported. Because $\left[{ }^{18} \mathrm{~F}\right]$ fallypride $\mathrm{BP}_{\mathrm{ND}}$ values exhibit significant variability across different regions [e.g., striatum vs prefrontal cortex (PFC)], we used variance estimates at the voxelwise level rather than the pooled variance used in typical parametric analyses (Dagher et al., 1998). Once significant clusters were identified, clusterwise $\% \Delta \mathrm{BP}_{\mathrm{ND}}$ values were extracted and entered into SPSS 19.0 for additional analysis.

Planned analyses. Given the results of our previous study suggesting that the direct effect of $d$-amphetamine on EEfRT task performance was strongest for low (12\%) probability trials (Wardle et al., 2011), our first analysis was to identify associations between $\% \Delta \mathrm{BP}_{\mathrm{ND}}$ and the proportion of high-effort choices during low-probability trials. This condition requires willingness to pursue rewards when facing both effort and probability costs. This was followed by an exploration of the relationship between $\% \Delta \mathrm{BP}_{\mathrm{ND}}$ and proportion of high-effort choices averaged across 
Table 3. Baseline and after $d$-amphetamine (AMPH) $\mathrm{BP}_{\mathrm{ND}}$ in all identified regions of interest

\begin{tabular}{|c|c|c|c|c|c|c|}
\hline \multirow[b]{2}{*}{ Region } & \multicolumn{2}{|c|}{ Baseline $\mathrm{BP}_{\mathrm{ND}}$} & \multicolumn{2}{|c|}{ AMPH BP ${ }_{N D}$} & \multirow[b]{2}{*}{$\% \Delta \mathrm{BP}_{\mathrm{ND}}$} & \multirow[b]{2}{*}{$p$ value } \\
\hline & Mean & SD & Mean & SD & & \\
\hline Left caudate & 15.33 & 0.02 & 14.50 & 1.61 & $-5.61 \%$ & 0.00034 \\
\hline vmPFC & 0.72 & 0.16 & 0.70 & 0.17 & $-1.92 \%$ & 0.29573 \\
\hline VIPFC & 0.67 & 0.12 & 0.62 & 0.14 & $-7.58 \%$ & 0.00080 \\
\hline $\begin{array}{l}\text { Inferior temporal } \\
\text { gyrus }\end{array}$ & 1.13 & 0.21 & 1.08 & 0.22 & $-4.15 \%$ & 0.01077 \\
\hline Left insula & 3.81 & 0.46 & 3.46 & 0.48 & $-9.23 \%$ & 0.00003 \\
\hline Right insula & 0.97 & 0.13 & 0.90 & 0.14 & $-6.83 \%$ & 0.00162 \\
\hline
\end{tabular}

low-probability trials (in which subjects have to overcome costs related to both effort and low probability), we first explored associations between $d$ - amphetamine-induced DA responses and proportion of high-effort choices during lowprobability trials only. This analysis revealed a strong positive association between $\% \Delta \mathrm{BP}_{\mathrm{ND}}$ in left caudate $(x=-8, y=10, z=14$, peak $Z$-score $=3.45, k=71, p_{\text {cluster }}<0.001$; all coordinates are given in the imaging space of the Montreal Neurological Institute (MNI), primarily encompassing the pre-commissural and postcommissural dorsal portion of this structure. In addition, high-effort choices were positively correlated with $\% \Delta \mathrm{BP}_{\mathrm{ND}}$ within a prefrontal network comprising bilateral ventromedial PFC (vmPFC) $(x=20$, $y=42, z=-18$, peak $Z$-score $=3.67, k=$
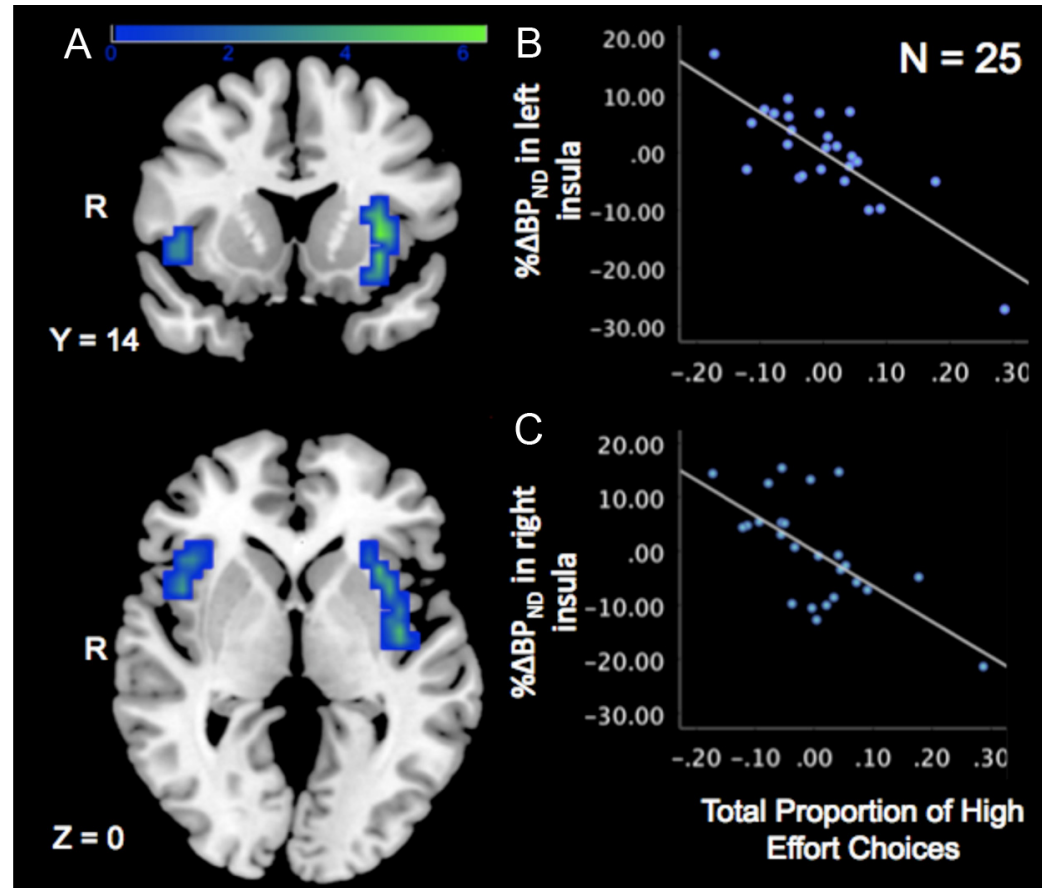
$\left.80, p_{\text {cluster }}<0.001\right)$ and left ventrolateral PFC (vlPFC) $(x=-48, y=18, z=6$, peak $Z$-score $\left.=3.13, k=44, p_{\text {cluster }}=0.005\right)$. We also observed a positive association between $\% \Delta \mathrm{BP}_{\mathrm{ND}}$ in the left inferior temporal gyrus and high-effort choices $(x=-56, y=-18$, $z=-22$, peak $Z$-score $=4.13, k=41, p_{\text {clus }^{-}}$ ter $=0.018$ ) (Fig. 2, Table 2). For each of these identified regions, the association between DA responses and high-effort choices was unchanged when the baseline $\mathrm{BP}_{\mathrm{ND}}$ was included in the model as a covariate, thereby ruling out the possibility that the observed associations were attributable to individual differences in basal $\mathrm{D}_{2} / \mathrm{D}_{3}$ binding as opposed to $\% \Delta \mathrm{BP}_{\mathrm{ND}}$. To assess the magnitude of stimulant-induced change in $\mathrm{D}_{2} / \mathrm{D}_{3}$ $\mathrm{BP}_{\mathrm{ND}}$ in these indentified areas, we tested the effects of $d$-amphetamine on $\mathrm{BP}_{\mathrm{ND}}$ within these regions. $d$-Amphetamine produced a significant decrease in $\mathrm{BP}_{\mathrm{ND}}$ in left caudate $(-5.6 \%)$, left vlPFC $(-7.6 \%)$, and left temporal cortex $(-4.2 \%)$ but not in vmPFC, which showed a nonsignificant decrease of $-1.9 \%$ (Table 3 ). No regions showed a significant inverse correlation between $\% \Delta \mathrm{BP}_{\mathrm{ND}}$ and the proportion of higheffort trials during the low-probability trials.

3. Relationship betweentotal proportion of high-effortchoicesand voxels showing significant inverse correlation between DA responses in bilateral insula and overall proportion of high-effort choices. $\boldsymbol{B}$, Scatter plot of DA responsivity in left insula and proportion of high-effort choices. $\boldsymbol{C}$, Scatter plot of DA responsivity in right insula and proportion of high-effort choices. Visualization threshold reflects correction for multiple comparisons, $t>2.5, k$ $>35$. Note that regression analyses are still significant when high-influence subject is removed (left, $b=-0.64, p=0.001$; right, $b=-0.53, p=0.014)$. $R$, right; color bar indicates $t$ value.

\section{DA sensitivity and EEfRT performance: all trials}

In addition to exploring just the low-

all probability levels, which examines individual differences in response to effort costs alone.

\section{Results}

\section{Behavioral results}

All subjects chose a combination of high-effort and low-effort options (mean \pm SD proportion of high-effort choices, $0.43 \pm$ 0.11 ). A single GEE model was used to test the effects of reward magnitude, probability, and expected value on choice behavior. Consistent with previous results using the EEfRT (Treadway et al., 2009; Wardle et al., 2011), each of these variables was a significant, independent predictor of choice behavior: reward magnitude, $b=0.69, p=0.001$; probability, $b=1.03$, $p=0.021$; expected value, $b=1.16, p=0.016$.

\section{DA sensitivity and EEfRT performance: low-probability trials only}

Based on our previous work indicating that the effects of $d$-amphetamine on EEfRT task behavior were strongest for probability trials, we also examined whether there were any associations between DA responses and the proportion of high-effort choices averaged across all probability levels. When we tested for positive associations, we did not identify any clusters that survived correction for multiple comparisons. In the negative direction, overall proportion of high-effort choices showed a strong inverse relationship with $\% \Delta \mathrm{BP}_{\mathrm{ND}}$ in bilateral anterior insula (left: $x=-24, y=22, z=10$, peak $Z$-score $=5.55, k=206$, $p_{\text {cluster }}<0.001$; right: $x=44, y=10, z=-2$, peak $Z$-score $=$ $3.41, k=50, p_{\text {cluster }}=0.022$ ), suggesting that greater DA sensitivity in these regions was associated with fewer high-effort (i.e., more low-effort) choices throughout the task (Fig. 3, Table 2). As above, we assessed whether the association between DA responsivity and high-effort choices was affected by the inclusion of baseline $\mathrm{BP}_{\mathrm{ND}}$ and found that it was not. We also explored the effects of $d$-amphetamine on $\mathrm{BP}_{\mathrm{ND}}$ in the insular regions and found that it produced significant decreases in $\mathrm{BP}_{\mathrm{ND}}$ in both left 
Table 4. Correlations and correlation comparisons for each probability level in all regions of interest

\begin{tabular}{|c|c|c|c|c|c|c|}
\hline \multirow[b]{2}{*}{ Region } & \multicolumn{3}{|c|}{$\begin{array}{l}\text { Probability condition } \\
\text { (Pearson's } r \text { ) }\end{array}$} & \multicolumn{3}{|c|}{$\begin{array}{l}\text { Correlation comparisons } \\
\text { (t statistic) }\end{array}$} \\
\hline & $88 \%$ & $50 \%$ & $12 \%$ & 88 vs $50 \%$ & 88 vs $12 \%$ & 50 vs $12 \%$ \\
\hline Left caudate & -0.24 & 0.30 & $0.69^{* * *}$ & $2.11^{*}$ & $3.5^{* *}$ & 1.67 \\
\hline vmPFC & -0.24 & 0.09 & $0.75^{* * *}$ & 1.32 & $3.98^{* * *}$ & $3.29 * *$ \\
\hline \multirow[t]{2}{*}{ Left vIPFC } & -0.13 & 0.27 & $0.71^{* * *}$ & 1.46 & $3.38^{* *}$ & $2.45^{*}$ \\
\hline & -0.21 & 0.27 & $0.64^{* *}$ & & 1.3 & $2.24^{*}$ \\
\hline Left insula & $-0.48^{*}$ & $-0.63^{* *}$ & -0.24 & -0.689 & 0.85 & 1.85 \\
\hline Right insula & $-0.47^{*}$ & $-0.46^{*}$ & -0.16 & 0.52 & 0.91 & 0.59 \\
\hline
\end{tabular}

and right insula, resulting in $-9.2 \%$ and $-6.8 \%$ changes, respectively (Table 3 ).

\section{Region of interest analysis across probability conditions}

Given that we identified different regions when we examined high-effort choices during low-probability trials only compared with high-effort choices averaged across all probability levels, we extracted estimates of $\% \Delta \mathrm{BP}_{\mathrm{ND}}$ for all identified regions and examined their association with the proportion of high-effort choices for each level of probability (controlling for age and gender). In addition, we tested whether there was a statistically significant difference between correlations at different probability levels for each region of interest (Table 4). Consistent with our voxelwise approach, regions identified in our low-probability analysis (left caudate, vmPFC, left vlPFC, and left temporal cortex) showed significant differences in $r$ values between the highand low-probability conditions. The same was true for $r$ values compared between the low- and medium-probability conditions for all extrastriatal areas. In contrast, regions identified in our analysis of all trials (right and left insula) showed no significant differences in $r$ values across any of the three probability levels.

\section{Discussion}

The present study provides novel evidence linking individual differences in DA responsivity to variation in human cost/benefit choice behavior. Positive associations between DA function and willingness to expend effort for larger rewards was strongest during low-probability trials, when subjects had to overcome both effort and probabilistic response costs. Two of the regions showing this association - the striatum and vmPFC — are known to be critically involved in multiple forms of cost/benefit decisionmaking (Hare et al., 2008; Botvinick et al., 2009; Croxson et al., 2009; Kable and Glimcher, 2009; McGuire and Botvinick, 2010). Interestingly, we also observed a strong inverse correlation between willingness to bear effort costs and DA responses in the bilateral insula. This pattern of findings suggests an important regional specificity in the relationship between DAergic function and individual differences in cost/benefit choice behavior.

\section{DA sensitivity in a corticostriatal network positively predicts high-effort choices}

In animal models, robust evidence indicates that DA-releasing agents help increase an organism's tolerance of costs that may discount the face value of a reward, such as effort required (Salamone et al., 2007), probability of receipt (St Onge and Floresco, 2009), or temporal delay (Wade et al., 2000). Further emphasizing the role of DA in specifically mitigating response costs, research has demonstrated that, when effort or probability costs are low (e.g., effort requirements of an fixed ratio 1 schedule), the impact of DA manipulation is minimal. However, the conse- quences of either DA enhancement or attenuation increase dramatically as response requirements rise and reward probabilities decline (Salamone et al., 2001; St Onge and Floresco, 2009). Similarly in humans, the effects of $d$-amphetamine administration on processing of effort and probability costs during the EEfRT are greatest for low-probability trials (Wardle et al., 2011).

Consistent with these previous preclinical and human findings, we observed the strongest positive association between DA sensitivity and willingness to work more for rewards during lowprobability trials, when subjects were required to overcome the maximum combination of effort and probabilistic response costs. In this analysis, we observed that DA responses in left striatum, as well as left vlPFC and bilateral vmPFC, were associated with a higher proportion of high-effort choices. This corroborates previous findings suggesting that striatal DA function is critical for effort-related behavior (Salamone et al., 2007).

In contrast to striatal DA, the role of DA within both vmPFC and vlPFC has received relatively less attention. Some evidence suggests that vmPFC DA function may be similarly required to maintain effortful responding for rewards (Cetin et al., 2004), as well as motivated performance of cognitively demanding tasks (Winstanley et al., 2010). More broadly, the vmPFC has been heavily implicated in both human and nonhuman primate studies as a key region involved in value-based decision-making, in which the individual must choose across multiple cost/benefit options (Kable and Glimcher, 2009; Noonan et al., 2010). Similarly, a number of studies also support a role for vlPFC in reward-based decision-making (Sakagami and Pan, 2007; McGuire and Botvinick, 2010). The current findings suggest that DA function within these regions contributes to individual differences in cost/benefit decision-making.

\section{Insula DA sensitivity positively predicts low-effort (fewer high-effort) choices}

Our study also identified the bilateral insula as a region in which greater DA responsivity was associated with more low-effort (i.e., fewer high-effort) options across all levels of probability. By averaging across probability levels, this analysis explored individual differences in sensitivity to effort expenditure alone. To our knowledge, the effects of DA depletion or enhancement in this region on motivated behavior have not been explored in animals. However, both lesion and neuroimaging studies highlight the importance of this structure in mediating motivation and cost/benefit decisionmaking. Functional MRI (fMRI) studies of reward learning have repeatedly highlighted bilateral anterior insula as an area involved in processing response costs (Kuhnen and Knutson, 2005; Knutson et al., 2007) as well as reward-dependent prediction errors (Pessiglione et al., 2006), which are generally thought to reflect phasic DA activity (Schultz, 2007). Neural activity in the insula during anticipation of losses has been found to predict subsequent acquisition of lossavoidance decision-making (Samanez-Larkin et al., 2008), and individuals with lesions to anterior insula show less sensitivity to changes in expected value during risk-based decision-making (Weller et al., 2009). Of particular note, a recent fMRI study exploring effort-based decision-making in humans found that increased bilateral insula activation was a strong predictor of choosing a low-effort option (Prévost et al., 2010). Although these studies do not directly assess DA function, it seems reasonable to speculate that these activation patterns may reflect, in part, DAergic signaling. The human insula receives relatively rich DA innervation (Gaspar et al., 1989) and expresses both $\mathrm{D}_{1}$-like and $\mathrm{D}_{2}$-like receptors (Hurd et al., 2001). On the whole, these data, together with the current findings, raise the intriguing possibility that the insula plays a key role in processing response costs and that DA signaling may contribute to this function. 
In addition to elucidating relationships between regionally specific variation in DA responsivity and individual differences in human cost/benefit decision-making, the present findings may help to identify mechanisms relevant to reward processing deficits in psychopathology. Alterations in cost/benefit decisionmaking have been heavily implicated in psychiatric illnesses that are associated with disrupted DA function, including disorders of mood and addiction (Volkow et al., 2004; Treadway and Zald, 2011). Depressed patients and individuals with self-reported motivational anhedonia show reduced willingness to expend effort for monetary rewards (Treadway et al., 2009; Kurniawan et al., 2010; Cléry-Melin et al., 2011), and catecholamine depletion in humans decreased effortful responding for drug rewards (Venugopalan et al., 2011). These complimentary lines of research emphasize the importance of DA in the pathophysiology of symptomatic choice behavior in clinical populations.

\section{Limitations}

Several limitations of this study warrant mention. First, although our analytical approach was informed by a previous study exploring the effects of $d$-amphetamine on EEfRT performance (Wardle et al., 2011), the current study did not examine the effects of $d$ amphetamine on EEfRT behavior in this sample; this would be of interest but would address a distinct question from the focus of the present work. A second potential concern is that the $\mathrm{D}_{2} / \mathrm{D}_{3}$ receptor ligand used in this study, $\left[{ }^{18} \mathrm{~F}\right]$ fallypride, is somewhat less sensitive to striatal DA release than $\left[{ }^{11} \mathrm{C}\right]$ raclopride (Morris and Yoder, 2007), which may have contributed to identifying fewer positive associations between EEfRT performance and DA responses in striatal regions than might be expected given past animal studies (Salamone et al., 2007). Nevertheless, studies have consistently indicated that $\left[{ }^{18} \mathrm{~F}\right]$ fallypride is able to detect significant $d$-amphetamine-induced displacement within the striatum (Riccardi et al., 2006; Morris and Yoder, 2007; Cropley et al., 2008; Slifstein et al., 2010), and the magnitude of this release has repeatedly been found to show meaningful correlations with behavioral variables (Buckholtz et al., 2010a,b; Woodward et al., 2011). Another issue is the observation that between $12 \%$ and $50 \%$ of subjects appeared to show negative $\% \Delta \mathrm{BP}_{\mathrm{ND}}$, depending on the region evaluated. Negative $\% \Delta \mathrm{BP} \mathrm{ND}_{\mathrm{ND}}$ indicates an increase in $\mathrm{D}_{2} / \mathrm{D}_{3}$ receptor availability after $d$-amphetamine, which is inconsistent with the predicted effects of the drug. However, the presence of negative $\% \Delta \mathrm{BP}_{\mathrm{ND}}$ is common in past PET imaging studies across different ligands and regions, making it unlikely to reflect purely methodological error (Volkow et al., 1997; Drevets et al., 2001; Leyton et al., 2002; Abi-Dargham et al., 2003; Martinez et al., 2003). More likely, this reflects individual variability in the duration and magnitude of amphetamine responses, which would be consistent with studies of reported subjective effects (de Wit et al., 1986). It is for this reason, however, that we interpret our data as reflecting DA "sensitivity" or "responsivity" rather than just DA release. We also note that the lack of counterbalancing in our design could have impacted $\% \Delta \mathrm{BP}_{\mathrm{ND}}$ if the novelty of the first scan day differentially caused DA release relative to the second scan day, which would reduce the magnitude of calculated $d$-amphetamine $\mathrm{BP}_{\mathrm{ND}}$ displacement. It is also theoretically possible that the administration of $\left[{ }^{18} \mathrm{~F}\right]$ fallypride during the first scan may have had effects on $\mathrm{BP}_{\mathrm{ND}}$ that carried over to the second scan, although this seems unlikely given the subpharmaceutical dose used. Finally, there have been some questions regarding the ability of $\left[{ }^{18} \mathrm{~F}\right]$ fallypride to detect $d$-amphetamine-induced displacement of $\mathrm{BP}_{\mathrm{ND}}$ in extrastriatal regions, particularly cortical areas (Cropley et al., 2008; Slifstein et al., 2010). However, a careful review of these studies indicates that $d$-amphetamine does in fact show expected decreases in $\left[{ }^{18} \mathrm{~F}\right]$ fally- pride $\mathrm{BP}_{\mathrm{ND}}$ across multiple areas, but variability is high in cortical regions, which diminishes the ability to detect a statistically significant effect of $d$-amphetamine in studies with modest samples.

\section{Conclusions}

In summary, the present paper provides novel evidence linking variation in human DA function with cost/benefit preferences. This is a crucial step in validating animal models of DA function and effortrelated behavior and extends the translational value of these preclinical paradigms by showing their association with individual differences in value-based decision-making processes that are known to be dysfunctional across multiple forms of psychopathology.

\section{References}

Abi-Dargham A, Kegeles LS, Martinez D, Innis RB, Laruelle M (2003) Dopamine mediation of positive reinforcing effects of amphetamine in stimulant naive healthy volunteers: results from a large cohort. Eur Neuropsychopharmacol 13:459-468.

Bardgett ME, Depenbrock M, Downs N, Points M, Green L (2009) Dopamine modulates effort-based decision making in rats. Behav Neurosci 123:242-251.

Bickel WK, Marsch LA (2001) Toward a behavioral economic understanding of drug dependence: delay discounting processes. Addiction 96:73-86.

Botvinick MM, Huffstetler S, McGuire JT (2009) Effort discounting in human nucleus accumbens. Cogn Affect Behav Neurosci 9:16-27.

Buckholtz JW, Treadway MT, Cowan RL, Woodward ND, Li R, Ansari MS, Baldwin RM, Schwartzman AN, Shelby ES, Smith CE, Kessler RM, Zald DH (2010a) Dopaminergic network differences in human impulsivity. Science 329:532.

Buckholtz JW, Treadway MT, Cowan RL, Woodward ND, Benning SD, Li R, Ansari MS, Baldwin RM, Schwartzman AN, Shelby ES, Smith CE, Cole D, Kessler RM, Zald DH (2010b) Mesolimbic dopamine reward system hypersensitivity in individuals with psychopathic traits. Nat Neurosci 13:419-421.

Cetin T, Freudenberg F, Füchtemeier M, Koch M (2004) Dopamine in the orbitofrontal cortex regulates operant responding under a progressive ratio of reinforcement in rats. Neurosci Lett 370:114-117.

Christian BT, Narayanan T, Shi B, Morris ED, Mantil J, Mukherjee J (2004) Measuring the in vivo binding parameters of $\left[{ }^{18} \mathrm{~F}\right]$-fallypride in monkeys using a PET multiple-injection protocol. J Cereb Blood Flow Metab 24:309-322.

Cléry-Melin ML, Schmidt L, Lafargue G, Baup N, Fossati P, Pessiglione M (2011) Why don't you try harder? An investigation of effort production in major depression. PLoS One 6:e23178.

Cousins MS, Salamone JD (1994) Nucleus accumbens dopamine depletions in rats affect relative response allocation in a novel cost/benefit procedure. Pharmacol Biochem Behav 49:85-91.

Cropley VL, Innis RB, Nathan PJ, Brown AK, Sangare JL, Lerner A, Ryu YH, Sprague KE, Pike VW, Fujita M (2008) Small effect of dopamine release and no effect of dopamine depletion on $\left[{ }^{18} \mathrm{~F}\right]$ fallypride binding in healthy humans. Synapse 62:399-408.

Croxson PL, Walton ME, O’Reilly JX, Behrens TE, Rushworth MF (2009) Effort-based cost-benefit valuation and the human brain. J Neurosci 29:4531-4541.

Dagher A, Gunn RN, Lockwood G, Cunningham VJ, Grasby PM, Brooks DJ (1998) Measuring neurotransmitter release with PET: methodological issues. In: Quantitative functional brain imaging with positron emission tomography (Carson RE, Daube-Witherspoon ME, Herscovitch P, eds). London: Academic.

de Wit H, Uhlenhuth EH, Johanson CE (1986) Individual differences in the reinforcing and subjective effects of amphetamine and diazepam. Drug Alcohol Depend 16:341-360.

Drevets WC, Gautier C, Price JC, Kupfer DJ, Kinahan PE, Grace AA, Price JL, Mathis CA (2001) Amphetamine-induced dopamine release in human ventral striatum correlates with euphoria. Biol Psychiatry 49:81-96.

Forbes EE, Shaw DS, Dahl RE (2007) Alterations in reward-related decision making in boys with recent and future depression. Biol Psychiatry 61:633-639.

Gaspar P, Berger B, Febvret A, Vigny A, Henry JP (1989) Catecholamine innervation of the human cerebral cortex as revealed by comparative 
immunohistochemistry of tyrosine hydroxylase and dopamine-betahydroxylase. J Comp Neurol 279:249-271.

Hall H, Sedvall G, Magnusson O, Kopp J, Halldin C, Farde L (1994) Distribution of D1- and D2-dopamine receptors, and dopamine and its metabolites in the human brain. Neuropsychopharmacology 11:245-256.

Hare TA, O’Doherty J, Camerer CF, Schultz W, Rangel A (2008) Dissociating the role of the orbitofrontal cortex and the striatum in the computation of goal values and prediction errors. J Neurosci 28:5623-5630.

Holt DD, Green L, Myerson J (2003) Is discounting impulsive?. Evidence from temporal and probability discounting in gambling and nongambling college students. Behav Processes 64:355-367.

Hurd YL, Suzuki M, Sedvall GC (2001) D1 and D2 dopamine receptor mRNA expression in whole hemisphere sections of the human brain. J Chem Neuroanat 22:127-137.

Kable JW, Glimcher PW (2009) The neurobiology of decision: consensus and controversy. Neuron 63:733-745.

Kessler RM, Mason NS, Jones C, Ansari MS, Manning RF, Price RR (2000) $\left[{ }^{18} \mathrm{~F}\right] \mathrm{N}$-allyl-5-fluoropropylepidepride (fallypride): radiation dosimetry, quantification of striatal and extrastriatal dopamine receptors in man. Neuroimage 11:S32.

Knutson B, Rick S, Wimmer GE, Prelec D, Loewenstein G (2007) Neural predictors of purchases. Neuron 53:147-156.

Kuhnen CM, Knutson B (2005) The neural basis of financial risk taking. Neuron 47:763-770.

Kurniawan IT, Seymour B, Talmi D, Yoshida W, Chater N, Dolan RJ (2010) Choosing to make an effort: the role of striatum in signaling physical effort of a chosen action. J Neurophysiol 104:313-321.

Lammertsma AA, Bench CJ, Hume SP, Osman S, Gunn K, Brooks DJ, Frackowiak RS (1996) Comparison of methods for analysis of clinical $\left[{ }^{11} \mathrm{C}\right]$ raclopride studies. J Cereb Blood Flow Metab 16:42-52.

Leyton M, Boileau I, Benkelfat C, Diksic M, Baker G, Dagher A (2002) Amphetamine-induced increases in extracellular dopamine, drug wanting, and novelty seeking: a PET/ $\left[{ }^{11} \mathrm{C}\right]$ raclopride study in healthy men. Neuropsychopharmacology 27:1027-1035.

Maes F, Collignon A, Vandermeulen D, Marchal G, Suetens P (1997) Multimodality image registration by maximization of mutual information. IEEE Trans Med Imaging 16:187-198.

Martinez D, Slifstein M, Broft A, Mawlawi O, Hwang DR, Huang Y, Cooper T, Kegeles L, Zarahn E, Abi-Dargham A, Haber SN, Laruelle M (2003) Imaging human mesolimbic dopamine transmission with positron emission tomography. Part II: Amphetamine-induced dopamine release in the functional subdivisions of the striatum. J Cereb Blood Flow Metab 23:285-300.

McGuire JT, Botvinick MM (2010) Prefrontal cortex, cognitive control, and the registration of decision costs. Proc Natl Acad Sci U S A 107:7922-7926.

Morris ED, Yoder KK (2007) Positron emission tomography displacement sensitivity: predicting binding potential change for positron emission tomography tracers based on their kinetic characteristics. J Cereb Blood Flow Metab 27:606-617.

Mukherjee J, Christian BT, Dunigan KA, Shi B, Narayanan TK, Satter M, Mantil J (2002) Brain imaging of 18F-fallypride in normal volunteers: blood analysis, distribution, test-retest studies, and preliminary assessment of sensitivity to aging effects on dopamine D-2/D-3 receptors. Synapse 46:170-188.

Mukherjee J, Christian BT, Narayanan TK, Shi B, Collins D (2005) Measurement of $\mathrm{d}$-amphetamine-induced effects on the binding of dopamine D-2/D-3 receptor radioligand, ${ }^{18} \mathrm{~F}$-fallypride in extrastriatal brain regions in non-human primates using PET. Brain Res 1032:77-84.

Noonan MP, Walton ME, Behrens TE, Sallet J, Buckley MJ, Rushworth MF (2010) Separate value comparison and learning mechanisms in macaque medial and lateral orbitofrontal cortex. Proc Natl Acad Sci U S A 107:20547-20552.

Pessiglione M, Seymour B, Flandin G, Dolan RJ, Frith CD (2006) Dopamine-dependent prediction errors underpin reward-seeking behaviour in humans. Nature 442:1042-1045.

Phillips PE, Walton ME, Jhou TC (2007) Calculating utility: preclinical evidence for cost-benefit analysis by mesolimbic dopamine. Psychopharmacology (Berl) 191:483-495.

Prévost C, Pessiglione M, Météreau E, Cléry-Melin ML, Dreher JC (2010) Separate valuation subsystems for delay and effort decision costs. J Neurosci 30:14080-14090.
Riccardi P, Li R, Ansari MS, Zald D, Park S, Dawant B, Anderson S, Doop M, Woodward N, Schoenberg E, Schmidt D, Baldwin R, Kessler R (2006) Amphetamine-induced displacement of $\left[{ }^{18} \mathrm{~F}\right]$ fallypride in striatum and extrastriatal regions in humans. Neuropsychopharmacology 31:1016-1026.

Richards JB, Zhang L, Mitchell SH, de Wit H (1999) Delay or probability discounting in a model of impulsive behavior: effect of alcohol. J Exp Anal Behav 71:121-143.

Rohde GK, Aldroubi A, Dawant BM (2003) The adaptive bases algorithm for intensity-based nonrigid image registration. IEEE Trans Med Imaging 22:1470-1479.

Sakagami M, Pan X (2007) Functional role of the ventrolateral prefrontal cortex in decision making. Curr Opin Neurobiol 17:228-233.

Salamone JD, Wisniecki A, Carlson BB, Correa M (2001) Nucleus accumbens dopamine depletions make animals highly sensitive to high fixed ratio requirements but do not impair primary food reinforcement. Neuroscience 105:863-870.

Salamone JD, Correa M, Farrar A, Mingote SM (2007) Effort-related functions of nucleus accumbens dopamine and associated forebrain circuits. Psychopharmacology (Berl) 191:461-482.

Samanez-Larkin GR, Hollon NG, Carstensen LL, Knutson B (2008) Individual differences in insular sensitivity during loss anticipation predict avoidance learning. Psychol Sci 19:320-323.

Schultz W (2007) Behavioral dopamine signals. Trends Neurosci 30:203-210.

Slifstein M, Kegeles LS, Xu X, Thompson JL, Urban N, Castrillon J, Hackett E, Bae SA, Laruelle M, Abi-Dargham A (2010) Striatal and extrastriatal dopamine release measured with PET and $[(18) F]$ fallypride. Synapse 64:350-362.

St Onge JR, Floresco SB (2009) Dopaminergic modulation of risk-based decision making. Neuropsychopharmacology 34:681-697.

Treadway MT, Zald DH (2011) Reconsidering anhedonia in depression: lessons from translational neuroscience. Neurosci Biobehav Rev 35:537-555.

Treadway MT, Buckholtz JW, Schwartzman AN, Lambert WE, Zald DH (2009) Worth the "EEfRT"? The effort expenditure for rewards task as an objective measure of motivation and anhedonia. PLoS One 4:e6598.

Venugopalan VV, Casey KF, O’Hara C, O'Loughlin J, Benkelfat C, Fellows LK, Leyton M (2011) Acute phenylalanine/tyrosine depletion reduces motivation to smoke cigarettes across stages of addiction. Neuropsychopharmacology 36:2469-2476.

Volkow ND, Wang GJ, Fischman MW, Foltin RW, Fowler JS, Abumrad NN, Vitkun S, Logan J, Gatley SJ, Pappas N, Hitzemann R, Shea CE (1997) Relationship between subjective effects of cocaine and dopamine transporter occupancy. Nature 386:827-830.

Volkow ND, Fowler JS, Wang GJ, Swanson JM (2004) Dopamine in drug abuse and addiction: results from imaging studies and treatment implications. Mol Psychiatry 9:557-569.

Votaw JR, Kessler RM, de Paulis T (1993) Failure of the three compartment model to describe the pharmacokinetics in brain of a high affinity substituted benzamide. Synapse 15:177-190.

Wade TR, de Wit H, Richards JB (2000) Effects of dopaminergic drugs on delayed reward as a measure of impulsive behavior in rats. Psychopharmacology (Berl) 150:90-101.

Wardle MC, Treadway MT, Mayo LM, Zald DH, de Wit H (2011) Amping up effort: effects of $d$-amphetamine on human effort-based decisionmaking. J Neurosci 31:16597-16602.

Weller JA, Levin IP, Shiv B, Bechara A (2009) The effects of insula damage on decision-making for risky gains and losses. Soc Neurosci 4:347-358.

Wells WM 3rd, Viola P, Atsumi H, Nakajima S, Kikinis R (1996) Multimodal volume registration by maximization of mutual information. Med Image Anal 1:35-51.

Winstanley CA, Zeeb FD, Bedard A, Fu K, Lai B, Steele C, Wong AC (2010) Dopaminergic modulation of the orbitofrontal cortex affects attention, motivation and impulsive responding in rats performing the five-choice serial reaction time task. Behav Brain Res 210:263-272.

Woodward ND, Cowan RL, Park S, Ansari MS, Baldwin RM, Li R, Doop M, Kessler RM, Zald DH (2011) Correlation of individual differences in schizotypal personality traits with amphetamine-induced dopamine release in striatal and extrastriatal brain regions. Am J Psychiatry 168:418-426.

Zeeb FD, Robbins TW, Winstanley CA (2009) Serotonergic and dopaminergic modulation of gambling behavior as assessed using a novel rat gambling task. Neuropsychopharmacology 34:2329-2343.

Zeger SL, Liang KY (1986) Longitudinal data analysis for discrete and continuous outcomes. Biometrics 42:121-130. 